\title{
Estancia de Luis Alonso, antes llamado Judá Pérez, en Galicia ${ }^{1}$
}

\author{
M. ${ }^{a}$ Gloria de Antonio Rubio \\ IEGPS, Centro Mixto CSIC. Xunta de Galicia
}

\begin{abstract}
RESUMEN
ABSTRACT

A pesar de que en la documentación gallega existen referencias, aunque claramente insuficientes, a la presencia judia desde el siglo xI, no es hasta el siglo xv cuando las noticias conservadas son lo suficientemente abundantes como para elaborar la biografía de algunos de los personajes más destacados. Tal es el caso de Judá Pérez.

Con este nombre se documentan dos personajes homónimos diferenciados por el ámbito cronológico en el que se desarrolla su actividad profesional. El primero desde el año 1423 a 1456, y el segundo desde el año 1476 a 1488, siendo este último Judá el objeto de este artículo.

La particularidad de este personaje no viene determinada por su actividad profesional -mayordomo de varias casas condales y señoriales y arrendadorrecaudador de rentas reales-, sino por la constatación documental de su conversión

al cristianismo, con el nombre de Luis Alonso, y la continuidad de su actividad proresional como arrendador de rentas reales.

Although there are some references in the Galician papers, even though clearly insufficient, about the Jewish presence since the XIth century, it is not until the $X V$ th century when the news preserved are abundant enough to write the biographies of some of the most distinguished figures of the time. Such is the case of Judá Pérez.

Two homonymous men are documented with this name, and they are distinguished by the period of time when they carried on their professional activities. The first one, since the year 1423 to 1456 , and the second one since 1476 to 1488; being this last one, Juda, the object of this article. The peculiarity of this person doesn't come from his professional activity, - administrator of several earls and lords, and lessor/ tax collector of royal revenues-, but from the documental confirmation of his conversion to Christianity, under the name of Luis Alfonso, and the continuation of his professional activity as a lessor of royal revenues.
\end{abstract}

"Este artículo ha sido desarrollado en el Instituto de Estudios Gallegos "Padre Sarmiento", dentro del proyecto de investigación Diccionario biográfico de la Galicia de los Trastámara, (1369-1480), dirigido por el Dr. Eduardo Pardo de Guevara y Valdés, director de este Instituto y financiado por la Fundación Pedro Barrié de la Maza. 


\section{PALABRAS CLAVE KEYWORDS}

Edad Media. Galicia, judios, conversos.

Middle Ages, Galicia, Jewish, converts.

Aunque la presencia aislada de judíos viviendo en Galicia se remonta a los años centrales del siglo XI, no es hasta el siglo xv cuando la documentación conservada permite esbozar la biografía, más o menos detallada, de algunos de los personajes judíos más importantes. Entre estos últimos destaca la figura de Judá Pérez, no sólo por su importante papel en la casa condal de Ribadavia, sino por ser uno de los pocos personajes judíos relacionados con Galicia de los que existe constancia documental de su conversión al cristianismo, del nombre cristiano adoptado - Luis Alonso--, y de la continuidad de su actividad profesional tras la conversión.

Judá Pérez, escrito con muy diferentes grafías, es un nombre que aparece en la documentación gallega a lo largo de todo el siglo $\mathrm{xv}$, aunque no de una manera ininterrumpida. Las noticias existentes se agrupan en torno a dos grandes períodos de tiempo, separados entre sí por casi veinte años de diferencia.

El primer periodo abarca desde el año 1423, cuando se recoge la existencia de unas cartas de pago signadas de la signal de Yhuda Peres ${ }^{2}$, hasta el año 1456 , momento en que éste no pagó las fianzas solicitadas por el rey Enrique IV para recaudar las alcabalas del obispado de Ourense y éstas revirtieron en Diego de $\mathrm{He}$ rrera, vecino de Madrid:

... E agora sabed que, por quanto el dicho Yuda Peres no contento de fianças las dichas alcavalas deste dicho anno de la data desta mi carta, ni de los otros dos annos postriomeros del dicho arrendamiento, los dichos mis contadores las tornaron al almoneda. E andando nella, las tomaron para mi, por çerta contia de maravedies, menos del preçio por quel dicho Yuda Peres de mi las tenia arrendadas, por quanto non se fallavan quen mas diese por ellas. E despues las arrendo de mi, por los dichos tres annos, Diego de Herrera, vesino de la villa de Madrid ....

La documentación no permite saber cuál fue el motivo por el que Judá Pérez no satisfizo las fianzas, si por dificultades económicas o por una decisión personal. Es necesario hacer constar que para que el rey aceptase el arrendamiento de una renta era necesaria una fianza. Una parte de la misma podía cubrirse utilizando los derechos de cobro que determinadas personas tenian de la hacienda regia; y la otra con bienes raíces siempre que no estuviesen situados ni en Galicia, ni en Asturias, ni en Vizcaya, debido a sus particularidades hacendísticas ${ }^{4}$. A esta especial limitación hay que unir la crítica situación económica por la que atravesaba Galicia, en palabras de Miguel Angel Ladero Quesada, en 1455 y 1456 se descontó a los

\footnotetext{
2 Antonio Rubio, M. G. de: Los judios en Galicia (1044-1492). A Coruña, Fundación Pedro Barrié de la Maza, 2005, pág. 390, doc. 40.

3 antonio Rueio, M. G. de: Los judios en Galicia ..., págs. 525-528, doc. 223.

4 Ladero Quesada, M. A.: La Hacienda Real de Castilla en el siglo XV. La laguna, Universidad de La Laguna, 1973, págs. 22-26.
} 
arrendadores 4.000 .000 sobre un total de 87.541 .000 por la quiebra de Galicia ${ }^{5}$. Por lo tanto, bien pudo ser que ante las presumibles dificultades de cobro derivadas de la difícil situación económica fuese el propio Judá Pérez el que renunciase voluntariamente al arrendamiento.

El 20 de octubre de 1476, tras casi veinte años sin ninguna referencia documental, reaparece el nombre de Judá Pérez, en esta ocasión al servicio de don Bernardino Pérez Sarmiento, conde de Ribadavia. Esta relación y su dedicación a los asuntos económicos de la casa condal marcarán la vida profesional de este segundo Judá Pérez, objeto de este artículo.

Poco es lo que se sabe de su vida familiar, excepto que tenía un hermano llamado Mosé Pérez, que estuvo casado, que fue padre de varios hijos y vecino de Ourense y de Villafranca de Valcárcel. Para ser considerado vecino en el siglo XV era necesario cumplir una serie de condiciones, tales como haber nacido en el lugar o bien residir en la población un cierto tiempo, tener posesiones de bienes inmuebles alli y ser admitido como tal por el concejo ${ }^{6}$.

En Ourense estuvo avecindado al menos hasta el año 1486, tal y como queda de manifiesto en un documento fechado el 13 de mayo de ese mismo año, que hace referencia al traspaso de unas alcabalas arrendadas por Alfonso Carrión a Mose Peres e a Yuda Peres, su hermano, judios, vesynos de la çibdad de Orense, que es en el dicho reyno de Galisya?.

Posteriormente, y, como consecuencia de la orden de apartamiento a barrios separados de los cristianos promulgada en 1480 por los Reyes Católicos en las cortes de Toledo, trasladó su domicilio a Villafranca de Valcárcel, donde obtuvo también la vecindad, puesto que el 6 de noviembre de 1488, se le menciona como vesino de la vylla de Villafranca de Valcáçar ${ }^{8}$.

El traslado de Ourense a Villafranca debió ocurrir entre el 13 mayo de 1486, última vez en que aparece como vecino de Ourense, y el mes de agosto de 1487. Esta últirna fecha se deduce del documento anteriormente citado, fechado el 6 de noviembre de 1488, en el que el propio Judá afirma que ha quinse meses o más que yo el dicho Yudá Peres mudé mi casa e muger y hijos y hasienda e me pasé de bybyenda a la dicha villa de Villafranca de Valcáçar, donde soy vesyno e morador.

Frente a la escasez de fuentes sobre su vida personal o familiar destacan las referencias a su vida profesional, que siempre estuvo relacionada con la mayordomía al servicio de diversas casas nobiliarias y con la recaudación de tributos, tanto señoriales como reales.

Ladero Quesada, M. A.: Idem, pág. 208

- Garcia de Valdeavellano, L.: Curso de historia de las instituciones españolas. Madrid, Alianza, 1992, pág. 543.

Antonio Rubio. M. G. de: Los judios en Galicia ..., págs. 565-566, doc. 273.

- Ferro Couselo, X.: A vida e a fala dos devanceiros. Vigo, Galaxia, 1996, reimpresión, tomo II, págs. 238-240, doc. 223. 
En su nivel palatino, el personal hacendístico tenía al frente al mayordomo mayor, cargo de origen altomedieval, como jefe de la casa del rey en sus aspectos económicos y financieros. Era un cargo más privado que público, aunque comienza a adquirir este último carácter desde finales del siglo X ${ }^{9}{ }^{9}$. Traspasando la organización palatina a la de una casa nobiliaria, se puede considerar que el mayordomo era el responsable de la casa en sus aspectos económicos y financieros, y como tal se documenta la presencia de Judá Pérez al senvicio de don Bernardino Pérez Sarmiento, conde de Ribadavia; de don Juan Pimentel, señor de Allariz; y del conde de Santa Marta.

El inicio de la actividad de Judá Pérez como mayordomo de don Bernardino Pérez Sarmiento, conde de Ribadavia, se recoge en una carta de foro datada en el año 1476 y realizada por el propio Judá Pérez: Sabeam quantos esta carta viren, como eu, Yhuda Peres, mayordomo e procurador que soo do meu sennor don Bernaldino Sarmiento, conde de Ribadavia, por sua carta de poder firmada de seu nomme e signada de escrivano publico, a qual aquí vay encorporada ... ${ }^{10}$.

El final de esta mayordomía no puede precisarse con exactitud, pero debió ocurrir entre los años 1479 y 1483 . En 1479 aún se registra su presencia en la casa condal cuando se menciona el cargo que se le fase en el dicho su mayordomado de Ribadavia deste año de setenta y nueve años ${ }^{11}$. En 1483 era su hermano Mosé Pérez el que actuaba como mayordomo de don Bernardino: Otro que hizo Mosen Perez, maiordomo del Conde de Rivadavia, a Fernan Codo y su Muger, de una fanega de centeno. data: Año de $1483^{12}$. Sin embargo, el hecho de que, como se verá mas adelante, en los primeros años de la década de 1480 a 1490 sea mayordomo de don Juan Pimentel y de que en 1482 lo sea del conde de Santa Marta de Ortigueira, permite suponer que el final de la mayordomía al servicio de la casa de Ribadavia estaría en torno a 1479.

Durante la permanencia de Judá Pérez al servicio de don Bernardino se da la particularidad de que uno de los principales documentos sobre su persona fue generado por él mismo. Así, el 24 de marzo de $1479^{13}$ entregó al conde una relación de cuentas donde se recoge su actividad como mayordomo; el período contable, desde 1477 a 1478; los ingresos y gastos de don Bernardino Pérez Sarmiento; y la responsabilidad que en los mismos tuvo Judá Pérez. Se inicia con el siguiente párrafo:

Relaçion de los maravedies e pan e vino e carne e toçinos e carneros e otras cosas que fueron a cargo del mayordomo Yuda Peres los años pasados de mill e

9 Ladero Quesada, M. A.: Fiscalidad y Poder Real en Castilla (1252-1369). Madrid, Editorial Complutense, 1993, pág. 232.

10 Antonio Rubio, M. G. de: Los judios en Galicia ..., pág. 546, doc. 252

11 Fernandez SuÁrez, G. F.: «Un ejemplo de hacienda nobiliaria gallega en el siglo xv: los ingresos y los gastos de don Bernardino Pérez Sarmiento, I Conde de Ribadavia, entre los años 1477-1478", Compostellanum, XLVIII, 1-4 (2003), pág. 604.

12 Antonio Rubio, M. G. de: Ibidem, pág. 556, doc. 260.

13 Fernández Suárez, G. F.: Ibidem, págs. 578-604. 
quatroçientos e setenta e syete e setenta e ocho años en su mayordomia de la villa y condado de Ribadavia e sus comarcas, asy de alcavalas como de portadgos e pedidos de San Juan e serviçios de anbos los dichos años e con el pedido del Rey que fue a su cargo e recabdo el año pasado de LXXVIII, segund que todo lo dio por su cuenta e por su libro que entrego firmado de su nonbre por ystenso declaradas todas las dichas rentas de anbos los dichos años, que monto su cargo dellos dos cuentos e tres mill e ochoçientos e setenta e tres maravedies e dos cornados, los quales dichos dos cuentos e tres mill e ochoçientos e setenta e tres maravedies e dos cornados el dicho Yuda Peres reçebio e recabdo de la dicha villa e condado de Ribadavia e sus comarcas en los dichos dos años de setenta e syete e setenta e ocho años, segund que adelante dira en esta guisa ...

A cambio de esta actividad recibió anualmente, para sí y para su escudero, un salario de 22.500 maravedies, 50 fanegas de centeno, 20 moyos de vino y 14 tocinos:

... tomo el dicho Yuda Peres para sy en cada uno de los dichos dos años para su raçion e quitaçion e para un escudero con que me syrvio veynte e dos mill e quinientos maravedies e çinquenta fanegas de centeno e veynte moyos de vino e catorse toçinos qu son en anbos los dichos años quarenta e çinco mill maravedies e çien fanegas de çenteno e quarenta moyos de vino e veynte e ocho toçinos ...

Además de las funciones anteriormente señaladas, Judá Pérez ejerció también como representante de don Bernardino en las negociaciones con el conde de Ribadaeo sobre la iguala del pedido del Rey. Las negociaciones tuvieron lugar en Betanzos y en Ourense donde gastaron en quatro dias que ally estovieron quatroçientos e ochenta maravedies e un puçal e medio de vino. Las funciones desarrolladas adquieren más importancia en tanto en cuanto el conde estaba ausente de Ribadavia durante todo el período contable, tal y como se deduce de los gastos de despensa. En 1477 se gastaron syete mill maravedies que me alcanço e gasto en mi despensa en quanto yo estuve en Gallisia y en 1478 que dio para la mi despensa desde veynte e tres de mayo del dicho año de setenta e ocho que yo llegue a Ribadavia fasta veynte e quatro de jullio que yo party para Castilla.

La actividad de Judá Pérez, al servicio de don Bernardino también tuvo consecuencias negativas para él ya que, junto a otros importantes personajes cristianos, fue excomulgado por la Iglesia Católica en el año 1479:

Bernaldino Xarmento, conde de Ribadavia, Juan Xarmento, merino de Roucos, Fernan de Sousa, escudero, Juan de la Cancela, mayordomo en el Chao de Castela y juda peres, mayordomo del conde y judio infiel": por los tributos impuestos, los daños causados a eclesiásticos y religiosos, etc., y, en especial, por haberse apoderado del lugar de la Quintaa en Cenlle y haber deshonrado a dicho racionero y al canonigo G. ${ }^{a}$ de Deza, el juez eclesiástico, con autoridad apostólica, ... excomulga a los dichos y manda que tal sentencia sea fijada en las gradas de hierro entre el coro y el altar de la catedral de Orense, después de haber sido leída en la procesión solemne, lo cual fue ejecutado al día siguiente y dos meses más tarde ${ }^{14}$.

14 Leirós Fernández, E.: Catálogo de los pergaminos monacales del archivo de la S. I. Catedral de Orense. Santiago de Compostela, El Eco Franciscano, 1951, pág. 426, doc. 4885. 
Las autoridades civiles y eclesiásticas cristianas podían ordenar a los tribunales judios imponer o hacer cumplir una excomunión o herem cuando se trataba de asuntos monetarios. La legislación judía también contempla la excomunión de aquellos miembros de la comunidad que no cumplieran las ordenanzas o no llevasen una vida adecuada a la ley y costumbres judías. Este era un castigo durísimo y podía llegar a causar la ruina social y económica del individuo. Aquél a quien se imponía el herem quedaba aislado de la sociedad y ningún judío, -ni sus propios familiares-, podía tener relación alguna con él, ni siquiera dirigirle la palabra ${ }^{15}$. La severidad y crueldad de este castigo dio lugar a la creación de castigos menores como el nidduy, que tan sólo duraba siete días, o la chemata, un grado aún menos grave ${ }^{16}$.

No es posible, con la documentación conservada, saber en qué medida afectó la excomunión a la vida cotidiana de Judá Pérez, aunque bien pudiera haber sido la clave del abandono de la mayordomía de la casa condal de Ribadavia y el traslado de Judá Pérez a Allariz al servicio de don Juan Pimentel.

Los Pimentel, condes de Benavente, mantuvieron a lo largo del siglo xv una política expansionista cuyo propósito incluía, entre otras, las tierras gallegas. El 12 de agosto de 1461 don Juan Pimentel, hijo del conde de Benavente, recibió el señorío de Allariz y su tierra en una solemne ceremonia celebrada en San Salvador de Pereira. Recibió, además, otros bienes señalados por su padre y que, por ser propios del mayorazgo, tuvieron que ser ratificados por su hermano mayor don Rodrigo, entonces ya nuevo conde de Benavente. Por otra parte, su matrimonio con doña Juana de Castro, hija de don Álvar, señor de Valdeflores y de la Puebla do Brollón, supuso una importante adquisición patrimonial ${ }^{17}$. A la muerte de don Juan sin un heredero varón, y a pesar de haber conseguido crear un mayorazgo, el señorío de Allariz revirtió a su procedencia ${ }^{18}$.

Sobre la actividad de Judá Pérez al servicio de don Juan Pimentel se conserva una única referencia fechada con posterioridad al momento de finalizar su mayordomía. A través de este documento, el rey don Fernando se dirige a las autoridades de Galicia para que determinen acerca del alquiler de unas casas de Gonzalo de la Canal que debía pagar Judá Pérez judyo, mayordomo que hera a la sazon de don Juan Pimentel.

Las casas en cuestión estaban situadas en la plaza de la villa de Allariz y habían sido alquiladas por un período de dos o tres años por Judá Pérez. Después de que éste abandonó Allariz vivió en ellas su hermano Mosé disfrutándolas, entre

${ }^{15}$ LACAVE, J. L.: "Aspectos de la sociedad judía en la España Medieval» en Xudeos e conversos na historia, Ribadavia, 1991, tomo II, pág. 23

16 Cantera Montenegro, E.: Aspectos de la vida cotidiana de los judios en la España medieval. Madrid, Universidad Nacional de Educación a Distancia, 1998, pág. 192

17 Pardo de Guevara y Valdés, E.: Los Señores de Galicia. Tenentes y condes de Lemos en la Edad Media. A Coruña, Fundación Pedro Barrié de la Maza, 2000, pág. 350.

${ }^{18}$ Garcia Oro, J.: La nobleza gallega en la Baja Edad Media. Santiago de Compostela, Bibliófilos Gallegos, 1981, pág. 71. 
los dos, ocho o nueve anos, poco mas o menos tenpo. Ante la falta de pago, Gonzalo de la Canal recurrió al rey y éste respondió con un documento fechado el 20 de agosto de 1489. Partiendo de esta fecha y, dado que se desconoce en qué momento Gonzalo de la Canal se dirigió al rey, se podría situar la mayordomía de Judá Pérez al servicio de don Juan Pimentel en los primeros años de la década 1480-1490.

Con posterioridad a estas fechas, pero inmediatamente después, se documenta también la actividad de Judá Pérez como mayordomo del conde de Santa Marta de Ortigueira. Este condado tiene su origen en 1442, cuando Diego Pérez Sarmiento (1427-1466) ${ }^{19}$ recibió la concesión real que le convirtió en su primer conde. A su muerte, al no tener hijos legítimos, se produjo una disputa entre sus hijos ilegítimos, -Garcia y Bernardino-, que culminó en 1476 con la cesión por parte de Bernardino del título condal de Santa Marta de Ortigueira a Francisco, hijo de Garcia, y el nombramiento de Bernardino como conde de Ribadavia ${ }^{20}$.

La relación de Judá Pérez con el conde de Santa Marta se refleja en un único documento, fechado en 1482, en el que textualmente se dice: et as quaes ditas casas de nos tina aforadas Yudá Peres, judío, mayordomo do conde de santa marta et as vendeu a Juan de Deça arçediano ... ${ }^{21}$, pero que no deja lugar a dudas sobre su actividad profesional desarrollada para la casa condal de Santa Marta de Ortigueira.

Unos años después, en $1486^{22}$, se registra de nuevo la presencia de Judá Pérez en la documentación gallega, pero en esta ocasión como arrendador de las alcabalas de Ribadavia: el dicho Afonso Carrion arrendo y traspaso las dichas alcabalas, por el tenpo e preçio e segund e en la manera e forma que de los dichos nuestros recabdadores los avia arrendado, a Mose Peres e a Yuda Peres, su hermano ...

Prácticamente todas las rentas reales se arrendaban a personas o grupos que pagaban al monarca un precio por ellas, fijado en subasta, y que corrían con todos los avatares y ventajas del cobro. Su beneficio consistía en la diferencia entre lo que efectivamente cobraban y lo que se habían comprometido a pagar al rey por la renta ${ }^{23}$. Según se desprende de la lectura del documento mencionado en el párrafo anterior, Alfonso de Carrión, alcalde de la villa de Mucientes, arrendó por cuatro años las alcabalas de Ribadavia, siendo sus fiadores el concejo y los ommes buenos de la dicha villa. Transcurridos dos años las traspasó a Mosé Pérez y a su hermano Judá, quienes se comprometieron mediante contrato a cumplir las condiciones establecidas. Sin embargo, cuando ambos fueron hechos presos, se

19 Fernández SuÁrez, G. F.: "Os Sarmiento durante a Baixa Idade Media: unha visión panorámica», Cadernos de Ribadavia, págs. 4-5.

20 Fernández Suarez, G. F.: La nobleza gallega entre los siglos XIV-xv. Los Sarmiento Condes de Ribadavia, Santiago de Compostela, El Eco Franciscano, 2002, págs. 205-209.

21 Antonio Rubio, M. G. de: Los judios en Galicia ..., pág. 556, doc. 259.

22 Antonio Rubio, M. G. de: Idem, págs. 565-566, doc. 273.

${ }^{23}$ Ladero Quesada, M. A.: La Hacienda Real ..., pág. 22. 
negaron a pagar la parte que les correspondía, por lo que algunos de los bienes de los fiadores de Alfonso de Carrión fueron embargados. Ante esta situación el concejo de Mucientes se dirigió a los Reyes Católicos solicitando que se hiciera ejecución en los bienes de Judá y Mosé Pérez, a lo que los Reyes accedieron.

En Ourense, el 6 de noviembre de 1488, tanto Judá Pérez como su hermano Mosé fueron requeridos por las autoridades orensanas para que abandonasen sus casas y se trasladasen a vivir a la juderia, separados de los cristianos. Alegando que eran vecinos de Villafranca de Valcárcel y de Allariz, respectivamente, recurrieron la orden de apartamiento y justificaron su presencia en la ciudad para poner recabdo en las rentas de las alcabalas de la dicha çibdad e su obispado, que tenemos arrendadas del Rey e de la Reyna, nuestros senores ${ }^{24}$.

Una vez arrendada una renta, los recaudadores eran los encargados de recibir el importe de la misma ${ }^{25}$. Como tal se recoge la presencia de Judá Pérez en 1484, ... paresçio don ludá Peres, recabdador del Rey e Reyna, nuestros señores ..., para reclamar la ejecución en los bienes de los fiadores de las alcabalas de a Costa de Sadur e Terra de Sayane y de las alcaualas de San Jurjo e Santa Locaya ${ }^{26}$.

La actividad profesional de Judá Pérez, en base a lo expuesto anteriormente, estuvo dedicada básicamente a la mayordomía de la casa condal de Ribadavia, de Santa Marta de Ortigueira y del señorío de Allariz, además de a la recaudación y arrendamiento de rentas reales. Sin embargo, lo que le diferencia de otros personajes judios relacionados con Galicia y de los que han quedado también noticias abundantes, es la constatación documental de su conversión al cristianismo y la continuidad de su actividad recaudatoria una vez convertido, tal como queda de manifiesto en el documento otorgado en Madrid el 15 de diciembre de 1497, que se incluye al final del texto.

En la documentación gallega medieval es muy difícil encontrar referencias directas a la conversión de judios. La excepción la constituye Mencía, hija de Abrahán, que se tornara cristiaa ${ }^{27}$, como consta en un documento de 1483 , otorgado por el concejo de Ourense, en el que declaraba ysento e libertado de todos los tributos a aquél que se casase con ella. Para identificar a los conversos, ante la evidente falta de documentación, hay que recurrir bien a las relaciones familiares, bien a los apodos con los que algunos personajes aparecen en la documentación, o bien a los usos onomásticos.

En algunos casos, en los propios documentos se especifica la filiación de un personaje concreto, pudiéndose afirmar su condición de converso cuando se registra un nombre cristiano en el seno de una familia judia. Sirva como ejemplo el

\footnotetext{
24 Ferro Couselo, X.; Op. Cit., tomo II, págs. 238-240, doc. 223.

25 Ladero Quesada, M. A.: La Hacienda Real..., págs. 21-22.

26 Ferro Couselo, X.: Op. Cit., tomo II, pág. 234, doc. 221.

27 López Carreira, A.: “O casamento de Mencia, xudía conversa", Murguia, 3 (2004), pág. 26.
} 
caso de Diego López, hijo de Judá Pérez (1423-1456) y hermano de Abrahán: Diego Lopes, fillo de Yuda Peres, recaudador, pedio aos ditos juises ... et pasoas Abraan, fillo de Yuda Peres, en preço ... ${ }^{28}$ o el caso de Abrafán, sobriño de joan fernandes prateiro ... ${ }^{29}$. En otros casos el nombre del personaje va seguido del apodo "judío" o «judeo", lo que puede estar haciendo referencia a su pasado judaico o al de sus antepasados y, por lo tanto, a su condición de converso: Rui Fernandes dito Jude $u^{30}$. Los usos onomásticos sirven también en otras ocasiones para reconocer la condición de converso de un personaje, como en el caso de García Álvarez, arrendador de los diezmos de los puertos del mar de Galicia. De él se conserva un único documento, datado en 1411, en el que se hace constar hasta tres veces que había cambiado su nombre por el de Garcia Álvarez: Garçia Alvares que soyan chamar Don Samuel Deus Ajuda; Garçia Alvares que a eses tenpos chamavan Don Samuel; y Don Samuel que agora he Garçia Alvares ${ }^{31}$. El uso del "don" por parte de un personaje laico que no ostenta un título nobiliario ${ }^{32}$, unido al nombre Samuel, de profundas raíces biblicas, que cambia por el de Garcia, de gran tradición cristiana, permite afirmar su condición de converso. En el caso concreto de Judá Pérez es el hecho de que cambiara su nombre judio, -Yuda Peres-, por otro cristiano, - Luys Alonso-, y que este cambio se haga constar en el documento, lo que permite hablar de su conversión al cristianismo.

Una vez cristiano, Luis Alonso continuó ejerciendo la actividad de arrendador de rentas reales, compartiendo en esta ocasión el arrendamiento con Juan de Herrera: Juan de Herrera e a Luys Alonso, que antes se solia dezir Yuda Peres, en çiertas rentas que ovieron arrendado de nos ... Las rentas arrendadas posiblemente se situarían en territorio gallego, puesto que en el documento aparecen como fiadores Galaor Mosquera, - casado con doña Isabel, hija a su vez del primer matrimonio del conde don Pedro 33 - y Alonso de Miranda, ambos gallegos: Sepades que Galaot Mosquera e Alonso de Miranda, gallegos, nos fisieron relaçion ...

De la solicitud de los reyes don Fernando y doña Isabel dirigida al corregidor de Madrid el 15 de diciembre de 1497 para que resolviera la demanda de Galaor Mosquera y Alonso de Miranda, se puede deducir que Juan de Herrera y Judá Pérez no habian cumplido con sus pagos y habian sido embargados los bienes de sus fiadores. Estos últimos se dirigieron a los reyes solicitando que ordenaran al corregidor de Madrid la ejecución en bienes de Juan Herrera.

28 Antonio Rubio, M. G. de: Los judíos en Galicia ..., págs. 434-435, doc. 138.

29 López Carreira, A.: "Contribución ó estudo da xudería ourensá baixomedieval" en Xudeos e Conversos, Ribadavia, 1991, tomo II, págs. 205-206, doc. 7.

30 Cabana Outeiro, A.: O Tombo $H$ da catedral de Santiago de Compostela. Documentos anteriores a 1397. Valga, 2003, págs. $51-52$, doc. 7 .

${ }^{31}$ Martinez Salazar, A.: Documentos gallegos del archivo municipal de La Coruña. Separata de la colección de documentos históricos del Boletín de la Real Academia Gallega. La Coruña, Litografía e imprenta Roel, 1915, págs. 24-27, doc. 4.

32 Antonio RuBio, M. G. de: "Onomástica y uso del "don" entre los judíos gallegos medievales", Estudios de Genealogia, Heráldica y Nobiliaria de Galicia, págs. 433-452.

33 Pardo de Guevara y Valdés, E.: Op. Cit., pág. 387. 
De las dificultades anteriormente expuestas para reconocer un converso se deduce la excepcionalidad del documento analizado, en el que no sólo se constata la conversión de Judá Pérez con el nombre de Luis Alonso, sino que, una vez convertido, continuó su labor como recaudador, posiblemente en tierras gallegas. Lo que viene a demostrar, una vez más, que cuando los judíos recibían el bautismo se integraban en la sociedad cristiana sin ningún tipo de cortapisas, convirtiéndose asi en una amenaza para los "cristianos viejos" y en objetivos del Santo Oficio de la Inquisición.

\section{APÉNDICE DOCUMENTAL}

1497, diciembre, 15. Madrid.

Carta de don Fernando y doña Isabel para que el corregidor de Madrid resuelva la demanda de Galaot Mosquera y de Alonso de Miranda, gallegos, que había fiado ciertas rentas a Juan de Herrera y a Luis Alonso, antes Ilamado Judá Pérez, los cuales no habían liquidado sus cuentas.

AGS, RGS, XIV, n. ${ }^{\circ} 2635$

Para que el corregidor de Madrid faga [azfeygar] a Juan de Herrera e Luiz Alonso ciertas contias de maravedis que deben.

Don Fernando e dona Ysabel etc. a vos el corregidor de la villa de Madrid o a vuestro alcalde en el dicho ofiçio e a cada uno de vos a quien esta nuestra carta fuere mostrada salud e gracia.

Sepades que Galaot Mosquera e Alonso de Miranda, gallegos, nos fisieron relaçion por su petiçion diziendo que ellos fiaron a Juan de Herrera e a Luys Alonso, que antes se solia dezir Yuda Peres, en çiertas rentas que ovieron arrendado de nos e diz que ellos an pagado e lastado por ellos e diz que agora ellos an pedido esecuçion ante vos en bienes del dicho Juan de Herrera por virtud del dicho custo, la qual diz que non quereis faser sin que vos muestren ley por donde la podeys faser en lo qual diz que sy asy pasase ellos resçibirian grande agravio e danno e nos suplicaron e pidieron por merçed çerca dello les mandasemos proveer mandado que pues en ellos se ovo faser exsecuçion e pagaron por los dichos Juan de $\mathrm{He}-$ rrera e Luis Alonso commo sus fiadores que fisiesedes la dicha exsecuçion en bienes del dicho Juan de Herrera e les fyziesedes pagar lo que ellos pagaron con mas las costas que los dichos Galaot Mosquera e Alonso de Miranda an lastado e pagado por los dichos Juan de Herrera e Luys Alonso ${ }^{34}$, commo sus fiadores, las contias de maravedis asy diz que estamos obligados e costrinados e apremiados a los dichos Luys de Herrera e Luys Alonso a que luego les paguen lo que asy por ellos fallades que ovieren pagado e lastado ${ }^{35}$ con mas las costas que sobre la di-

\footnotetext{
34 Tachado: 0.

35 Tachado: gas.
} 
cha cabsa se les [retreaeren] faziendo e administrando sobre todo a amvas las dichas partes conplimiento de justicia e los unos nin los otros non fagades ende al por alguna manera su pena de la nuestra merçed e de diez mil libras para la nuestra camara.

Dada en la villa de Madrid a XV dias del mes de diziembre anno del nasçemiento de nuestro senor Ihesu Christo de I V CCCC XC VII annos. Iohanes, episcopus astorien lohanes dotor, Andres dotor, Françiscus doctor lohanes liçenciatus. Yo Bartolome Ruis de Castanneda, escrivano del Rey e de la Reyna nuestros sennores. La fize escrivir por su mandado con acuerdo de los del su consejo. 